\title{
Editorial for Applied Practices: Perspectives from the Field Section within the Journal of Psychologists and Counsellors in Schools edited by Associate Professor Susan Colmar
}

In this issue of the journal I am pleased to present a paper for Applied Practices by Christine Bhat on the highly topical issue of proactively preventing cyberbullying and sexting. Importantly, these two areas of concern occur commonly in our schools, particularly in secondary contexts, making this paper timely and helpful for practitioners. For example, I found the legal implications and potential recourse material very interesting, and could see that psycho-educational approaches, such that young people were made aware of the wider ramifications of cyberbullying and sexting, would be invaluable. The notion, which was new to me, of digital citizenship, ensuring young people "engage positively, know their online world, and choose consciously" is impressive as these principles of positive engagement, knowledge and choice can apply across other areas pertinent to the students we work with. Bhat addresses and explores four key areas of proactive prevention: school climate, policy, training online disinhibition, and promoting positive use of technology. I would commend this paper to you all as a resource to guide your own dealings and discussions on these critical topics of cyberbullying and sexting.

Applied Practices' requirements are noted below. In this section of the journal, papers need to have an applied focus, with scope for colleagues to offer papers such as:

Small scale evaluations of practice, where the findings are interesting and noted as preliminary and worthy of further exploration, even if these are not methodologically at the standard required for contributions to the main journal (e.g., no control group).

$>$ Conceptual or research literature reviews with implications for practice, with a specific reflective argument addressing practice, possibly provocatively.

$>$ Linked case studies in therapeutic, learning, and behaviour areas of intervention integrated around a common theme.

Sources might include reports from presentations, work in progress where preliminary data is reported allowing the author to submit full findings later, 
and adapted students' assignments. Appropriately selected peer reviewers referee papers.

Review guidelines include the following:

1. The article is of interest and relevance to members.

2. It is well written, properly referenced using APA $6^{\text {th }}$ edition guidelines, and is grammatical.

3. It has a literature base supporting the work's findings and/or thinking.

4. It is approximately 3000 words.

5. It may contain a 120 -word abstract.

6. It has a clearly articulated argument and looks to future directions etc.; thus, the work is beyond simple description, and needs to be analytical and possibly critical in its approach.

Please submit via Scholar 1 https://mc.manuscriptcentral.com/jgc

Can I encourage you the reader to write for us or to encourage and cajole colleagues to write for us. Seeing your name in print is always a thrill and Applied Practices makes this option available to everyone in the field.

Susan Colmar

Associate Professor Susan Colmar, PhD I Program Director for School Counselling/ School Psychology Sydney School of Education and Social Work THE UNIVERSITY OF SYDNEY Room 805, Education Building A35 I The University of Sydney I NSW | 2006 T +6129351 6265 | F +61293512606 E susan.colmar@sydney.edu.au I W http://sydney.edu.au 